\title{
Human epidermal growth factor-expressing mesenchymal stem cells reduce matrix metalloproteinase-1 expression via the mitogen- activated protein kinase pathway in human keratinocyte $\mathrm{HaCaT}$ cells
}

Jeong Hyun Lee

Gachon University

Chang Min Lee

Gachon University

Yong Jun Choi

Gachon University

See-Hyoung Park

Hongik University - Jochiwon Campus: Hongik University - Sejong Campus

Myeong Jin Nam ( $\sim$ genetx@hanmail.net )

Gachon University https://orcid.org/0000-0002-6966-9218

\section{Research Article}

Keywords: conditioned media, human epidermal growth factor, MAPK pathway, matrix metalloproteinase

Posted Date: July 29th, 2021

DOl: https://doi.org/10.21203/rs.3.rs-716671/v1

License: (c) (1) This work is licensed under a Creative Commons Attribution 4.0 International License. Read Full License 


\section{Abstract}

Mesenchymal stem cells (MSCs) repair tissue injury by upregulating the paracrine secretion of cytokines and growth factors. In this study, we examined the effect of human epidermal growth factor-transfected MSCs (hEGF MSCs) on human keratinocyte HaCaT cell proliferation and the mechanisms that regulate matrix metalloproteinase (MMP)-1 expression in HaCaT cells. To identify the hEGF plasmid and its transfection into MSCs, we performed gel electrophoresis and quantitative PCR. Proliferation and migration of HaCaT cells were examined using WST-1 and wound-healing assays, respectively. Zymography was performed to investigate the correlation between hEGF MSC-conditioned medium (CM)treated $\mathrm{HaCaT}$ cells and MMP-1 expression. We found that cell viability and wound-healing rates were increased in hEGF MSC-CM-treated HaCaT cells compared to those in MSC-CM-treated cells, and conversely collagenase activity was decreased. The mRNA and protein levels of MMP-1 were also decreased in hEGF MSC-CM-treated HaCaT cells. 2-DE analysis showed that the expression of carboxypeptidase, which promotes growth factors and wound healing, was increased in hEGF MSC-CMtreated HaCaT cells. Finally, western blotting was used to determine whether MMP-1 expression was reduced via the mitogen-activated protein kinase (MAPK) pathway; the results showed that the levels of MAPK pathway-related proteins ( $p E r k, p J N K$, and p-p38) and the levels of transcription factors (pCREB, $\mathrm{NFKB}$, and p-c-Fos) were decreased. In addition, pAkt expression was found to be elevated. The results of our study suggest that hEGF MSCs promote cell proliferation and reduce MMP-1 expression via the MAPK pathway in human keratinocyte HaCaT cells.

\section{Introduction}

Mesenchymal stem cells (MSCs) are multipotent progenitor cells that can differentiate into various lineages, such as the cartilage, bone tissues, and adipose tissues [1]. These cells were first discovered in the bone marrow and can be isolated from circulating blood, diverse non-hematopoietic tissues, and connective tissues [2,3]. Several studies have shown that MSCs have the potential for the treatment of various disorders such as autoimmune disease, myocardial infarction, spinal cord injury, bone injury, type 1 diabetes, and Alzheimer's disease [4]. Interestingly, recent studies have shown that MSCs can also repair tissue injury by upregulating the paracrine secretion of cytokines and growth factors [5]. Furthermore, MSC-conditioned medium (MSC-CM), which contains various cytokines and growth factors, has been shown to be safer and more effective than MSCs [6].

Growth factors (GFs), such as epidermal growth factor (EGF) and hepatocyte growth factor (HGF), are composed of various polypeptides, and their main function is to mediate cell proliferation through paracrine effects [7]. In particular, EGF, which has a low molecular weight ( $M W=6,045)$, has an important role in epithelial cell proliferation [8]. Binding of the ligand, including EGF, to the EGF receptor (EGFR) induces auto-phosphorylation at several C-terminal tyrosine residues leading to the recruitment of adaptor proteins that are involved in signal transduction to cytoplasmic effector proteins [9]. EGF triggers many cell signaling pathways, including phosphatidylinositol 3-kinase (PI3K), Akt, and mitogen-activated protein kinase (MAPK) [10] pathways. Recent studies have shown that EGF promotes cell proliferation. 
For example, EGF induces phosphorylation of serine 897 (S897) in EphA2, a member of the Eph receptor tyrosine kinase family, via the MAPK pathway that is required for EGF-induced cell proliferation [11].

Matrix metalloproteinases (MMPs) are zinc-dependent endopeptidases that regulate the proteolysis of extracellular matrix (ECM) and are secreted by keratinocytes. MMPs play an important role in embryonic development, neurological processes, wound healing, angiogenesis, arthritis, cardiovascular diseases, and cancer [12]. MMPs are classified into five major groups based on their functions: collagenase (MMP1, MMP-8, and MMP-13), gelatinase (MMP-2 and MMP-9), stromelysins (MMP-3, MMP-10, and MMP-11), matrilysins (MMP-7 and MMP-26), and membrane-type MMPs (MMP-14, MMP-15, and MMP-16) [13]. The expression of MMP-1 is regulated by the MAPK pathway [14]. Collagen, which is degraded by MMP-1, is located in the subepithelial and dermal layers of the skin. It provides structural support to living organisms and assists in cell attachment and migration [15]. Therefore, collagen is the most important factor in skin cell proliferation.

Our study showed that hEGF MSCs promote proliferation and migration of keratinocyte HaCaT cells and regulate the mechanisms underlying MMP-1 expression via the MAPK pathway.

\section{Materials And Methods}

\subsection{Plasmid preparation}

Competent cells transformed with pEGFP-N1 and pEGFP-N1-hEGF plasmids were cultured in $600 \mathrm{~mL}$ of lysogeny broth (LB) containing kanamycin $(100 \mu \mathrm{g} / \mathrm{mL})$ for $18 \mathrm{~h}$. The plasmid were extracted using the Plasmid DNA Purification Kit (Intron, Korea). The plasmids ( $4 \mu \mathrm{g}$ each) were then incubated with $20 \mu \mathrm{L}$ of enzyme solution containing $2 \mu \mathrm{L}$ restriction enzyme buffer, $0.2 \mu \mathrm{L}$ BSA, and $5 \mu$ g restriction enzyme (Cell signaling, USA) for $4 \mathrm{~h}$ at $37^{\circ} \mathrm{C}$. After $4 \mathrm{~h}$, the plasmids were loaded on a $1.5 \%$ agarose gel and electrophoresed at $100 \mathrm{mV}$ for $20 \mathrm{~min}$.

\subsection{Cell lines and cell culture}

The human keratinocyte HaCaT cell line and human umbilical cord blood-MSCs were purchased from the Korean Cell Bank (Korea) and Medipost Inc. (Korea). HaCaT cells and MSCs were cultured in Dulbecco's modified Eagle's medium (DMEM; GIBCO, USA) and minimum essential medium Alpha medium (MEM-a; Gibco, USA) with $1 \%$ penicillin/streptomycin and $10 \%$ fetal bovine serum, respectively (100 $\mathrm{mm}$ plates, $37^{\circ} \mathrm{C}, 5 \% \mathrm{CO}_{2}$, in a humidified incubator).

\subsection{Transfection and generation of conditioned medium (CM)}

MSCs were grown in $100 \mathrm{~mm}$ plates $\left(1.5 \times 10^{6}\right.$ cells/well, $10 \mathrm{~mL}$ medium). Next, the cells were transfected with $15 \mu \mathrm{g}$ of pEGFP-N1 or pEGFP-N1-hEGF plasmid using $20 \mu \mathrm{L}$ of Lipofectamine 2000 (Invitrogen, USA) in $10 \mathrm{~mL}$ Opti-MEM medium (GIBCO, USA), and incubated at $37^{\circ} \mathrm{C}$ for $6 \mathrm{~h}$. After that, the Opti-MEM medium was replaced with MEM-a (10\% FBS) and the cells were allowed to stabilize for $24 \mathrm{~h}$. 
The media was then replaced with fresh FBS-free MEM- $\mathrm{a}$ media and the cells were cultured for $72 \mathrm{~h}$ (72 $\mathrm{h}$ $\mathrm{CM}$ ) or $96 \mathrm{~h}$ ( $96 \mathrm{~h} \mathrm{CM}$ ) to obtain the CM. The supernatants from cultured MSCs, pEGFP-N1-transfected MSCs (Vector MSCs), and pEGFP-N1-hEGF-transfected MSCs (hEGF MSCs) were loaded in 3 kDa Amicon tubes (Millipore, USA) and centrifuged (5000 × g, $4^{\circ} \mathrm{C}, 60 \mathrm{~min}$ ). MSC CM, Vector MSC CM, and hEGF MSC $\mathrm{CM}$ were stored at $-80^{\circ} \mathrm{C}$ until use.

\subsection{Cell proliferation assay (WST-1)}

$\mathrm{HaCaT}$ cells were plated in a 96-well plate at a density of $5 \times 10^{3}$ cells/well. After $24 \mathrm{~h}$, cells were treated with various concentrations of $72 \mathrm{~h}$ or $96 \mathrm{~h} \mathrm{CM}(2 \%, 4 \%$, and $8 \%)$ for 24 or $48 \mathrm{~h}$. The cells were then treated with $10 \mu \mathrm{L}$ of WST-1 solution (DogenBio, Korea) in $100 \mu \mathrm{L}$ of DMEM, and incubated at $37^{\circ} \mathrm{C}$ for 2 h. The absorbance was measured at $450 \mathrm{~nm}$ using a microplate reader.

\subsection{Wound-healing assay}

HaCaT cells were plated in a 24 -well plate at a density of $7 \times 10^{4}$ cells/well. After $24 \mathrm{~h}$, the center of the monolayer was scraped with a pipette tip to create a scratch and cells were washed with PBS to remove the detached cells. The cells were then treated with various concentrations of $72 \mathrm{~h}$ or $96 \mathrm{~h} \mathrm{CM}(2 \%, 4 \%$, and $8 \%$ ) for $12 \mathrm{~h}$. Wound closure was observed under a microscope (Olympus CKX41, Japan). The wound-healing rates were quantified using Image $\mathrm{J}$ software (National Institutes of Health, USA).

\subsection{Quantitative polymerase chain reaction (qPCR)}

Total RNA was extracted from HaCaT cells using RNAiso (Takara, Japan) and cDNA was synthesized using a cDNA Synthesis Kit (Philekorea, Korea). Next, qPCR was performed using the QuantiSpeed SYBR No-ROX Kit and consisted of the following steps: 40 cycles of amplification at $90^{\circ} \mathrm{C}$ (denaturation), $59^{\circ} \mathrm{C}$ (annealing), and $72^{\circ} \mathrm{C}$ (extension). The MMP-1 PCR primer sequences used in the study were as follows:

Forward primer: 5'-GAGATCATCGGGACAACTCTCCTT-3'

Reverse primer: 5'-GTTGGTCCACCTTTCATCTTCATCA-3'

\subsection{Collagen zymography}

HaCaT cells were treated with $8 \% \mathrm{CM}$ from MSCs, Vector MSCs, and hEGF MSCs. The cell supernatants were collected and centrifuged $\left(5000 \times \mathrm{g}, 4^{\circ} \mathrm{C}, 60 \mathrm{~min}\right)$ in a $3 \mathrm{kDa}$ Amicon tube. The protein samples were separated on a $6 \%$ gel (copolymerized with $6.72 \mathrm{mg}$ collagen, Discovery Labware, USA) by sodium dodecyl sulfate-polyacrylamide gel electrophoresis (SDS-PAGE) at $100 \mathrm{~V}$ for $4 \mathrm{~h}$. Next, the gel was washed with $2.5 \%$ Triton $\mathrm{X}-100$ at $37^{\circ} \mathrm{C}$ to remove the SDS and then incubated in the developing solution at $37^{\circ} \mathrm{C}$ for $16 \mathrm{~h}$. Finally, the gels were stained with Coomassie Blue staining solution. The unstained areas (white bands) represent areas with collagenase activity. The unstained areas were quantified using the ImageJ software (National Institutes of Health, USA).

\subsection{Two-dimensional electrophoresis (2-DE) and matrix- assisted laser desorption/ionization-time-of-flight (MALDI-}




\section{TOF)}

Vector and hEGF CM-treated HaCaT cells were lysed in lysis buffer (containing urea, protease inhibitor, and thiourea), and the samples were quantified using the Bradford assay. After that, dry strips were treated with protein samples for $16 \mathrm{~h}$ (rehydration step), and isoelectric focusing (IEF) was performed using an Ettan IPGphor II Isoelectric Focusing System (GE Healthcare, USA). Following the IEF step, iodoacetamide and DTT were used to equilibrate the $\mathrm{pH}$ gradient strips. The strips were loaded onto a $12.5 \%$ SDS polyacrylamide gel and an Ettan DALTsix Vertical Electrophoresis Machine (GE Healthcare, USA) was used to separate the proteins based on their molecular weights. The gel was stained with Coomassie Blue staining solution. After picking the protein spots, they were treated with $200 \mu \mathrm{M}$ ammonium bicarbonate, and MALDI-TOF was conducted using a Voyager-DE STR MALDI-TOF Mass Spectrometer (Applied Biosystems, USA). Proteins were identified using the Swiss-Prot database.

\subsection{Western blot analysis}

HaCaT cells were treated with $8 \%$ CM from MSCs, Vector MSCs, and hEGF MSCs for $24 \mathrm{~h}$, washed with PBS, and lysed in radioimmunoprecipitation assay (RIPA) buffer (Cell Signaling, USA) containing DTT, PMSF, and protease inhibitor. The lysates were loaded onto a 12\% SDS-PAGE gel and electrophoresed for $2 \mathrm{~h}$. The gels were then transferred onto a nitrocellulose membrane. After blocking with $3 \%$ BSA, the membranes were incubated with primary antibodies at $4^{\circ} \mathrm{C}$ for $16 \mathrm{~h}$ and then with the corresponding secondary antibodies at room temperature for $2 \mathrm{~h}$. After incubation, protein bands were detected using ChemiDoc (Bio-Rad, USA).

\subsection{Statistical analysis}

All data are presented as the mean \pm SD of three independent experiments. Statistical analysis was performed using Student's $t$-test. Statistical significance was set at $\mathrm{p}-<0.05$.

\section{Results}

\subsection{Verification of pEGFP-N1 and pEGFP-N1-hEGF plasmids}

To verify the pEGFP-N1 and pEGFP-N1-hEGF plasmids following plasmid DNA purification (midi-PREP), we subjected them to agarose gel electrophoresis. pEGFP-N1 plasmid was $4.7 \mathrm{~kb}$ in size and contained only one restriction enzyme site for Nhe1, Xho1, EcoR1, Kpn1, and BamH1. pEGFP-N1-hEGF plasmid, which contained the cloned hEGF sequence $(3.6 \mathrm{~kb})$, was approximately $8.3 \mathrm{~kb}$ in length (Fig. 1A). This plasmid contained two restriction sites for EcoR1 and BamH1. Restriction digestion with EcoR1 yielded 4.3 and $3.5 \mathrm{~kb}$ fragments, and digestion with BamH1 yielded 5 and $2.5 \mathrm{~kb}$ fragments (Fig. 1B). The results showed that all the fragment sizes observed matched the expected sizes.

\subsection{Confirmation of hEGF mRNA expression in transfected MSCs}


To confirm that the Lipofectamine-mediated transfection of MSCs with the hEGF plasmid was successful, we performed qPCR assay to determine the level of EGF mRNA in hEGF-transfected MSCs compared to that in the controls (MSCs and vector-transfected MSCs). The results showed that the mRNA expression of hEGF was increased $4.0 \times 10^{4}$ and $1.0 \times 10^{5}$ times in hEGF MSCs compared to that in MSCs at $72 \mathrm{~h}$ and $96 \mathrm{~h}$, respectively (Fig. 2).

\subsection{Treatment with hEGF MSC-CM induced proliferation of human keratinocyte HaCaT cells}

We conducted a WST-1 assay to determine the effect of 2, 4, and 8\% CM treatment on the viability of HaCaT cells. As shown in Fig. 3A, HaCaT cells were treated with $72 \mathrm{~h} \mathrm{CM}$ from MSCs, Vector MSCs, and hEGF MSCs for $24 \mathrm{~h}$. The viability rate of HaCaT cells treated with $8 \% \mathrm{CM}$ from the three groups of MSCs were $100 \%, 102 \%$, and $115 \%$, respectively. As shown in Fig. 3B, cell viability rates were $100 \%, 109 \%$, and $133 \%$ in cells treated with $8 \% \mathrm{CM}$ for $48 \mathrm{~h}$. Figure $3 \mathrm{C}$ shows HaCaT cells treated with $96 \mathrm{~h} \mathrm{CM}$. Cell viability rates were $100 \%, 116 \%$, and $147 \%$ in cells treated with $8 \% \mathrm{CM}$ for $24 \mathrm{~h}$. As shown in Fig. 3D, cell viability rates were $100 \%, 110 \%$, and $148 \%$ in cells treated with $8 \% \mathrm{CM}$ for $48 \mathrm{~h}$. Based on these results, $8 \% \mathrm{CM}$ treatment was found to be more effective on cell proliferation than $2 \%$ and $4 \% \mathrm{CM}$. The viability of hEGF MSC-CM-treated HaCaT cells was higher than that of MSCs and Vector MSC-CM-treated cells.

\subsection{Treatment with hEGF MSC-CM induced migration of human keratinocyte HaCaT cells}

We performed a wound-healing assay to determine the effect of hEGF MSC-CM on migration of HaCaT cells. As shown in Figs. 4A and C, HaCaT cells were treated with $72 \mathrm{~h} \mathrm{CM}$ from MSCs, Vector MSCs, and hEGF MSCs for $12 \mathrm{~h}$. The wound-healing rates were $100 \%, 108 \%$, and $140 \%$ in cells treated with $2 \% \mathrm{CM}$, and $100 \%, 94 \%$, and $125 \%$ in cells treated with $4 \% \mathrm{CM}$. The wound-healing rates of HaCaT cells treated with $8 \% \mathrm{CM}$ did not change significantly. $\mathrm{HaCaT}$ cells were also treated with $96 \mathrm{~h} \mathrm{CM}$ from the three groups (Figs. 4B and D). The wound-healing rates in $2 \%$ CM-treated cells were $100 \%, 112 \%$, and $133 \%$, respectively. In addition, the wound-healing rates were $100 \%, 112 \%$, and $126 \%$ in cells treated with $4 \% \mathrm{CM}$, and $100 \%, 102 \%$, and $115 \%$ in cells treated with $8 \%$ CM.

\subsection{Protein expression in $\mathrm{HaCaT}$ cells treated with $\mathrm{CM}$ from Vector MSCs or hEGF MSCs}

To examine the differential protein expression between Vector MSC and hEGF MSC 8\% CM-treated HaCaT cells, we performed 2-DE proteomic analysis. Following gel electrophoresis and Coomassie Blue staining, we detected approximately 60 differential protein spots (Fig. 5). Among these protein spots, we selected four spots that were significantly different between the groups. The spots were picked and analyzed via MALDI-TOF. The expression levels of retention in endoplasmic reticulum sorting receptor 1 (RER1; secretory pathway), carboxypeptidase (growth factor promotion and wound healing), and 
triosephosphate isomerase (glycolysis, energy production) were found to be upregulated, whereas that of cytochrome bcl complex (inhibition of apoptosis) was found to be downregulated (Table 1).

Table 1

Identification of differentially expressed proteins spots in the Vector MSC-CM and hEGF MSC-CM-treated HaCaT cells.

\begin{tabular}{|c|c|c|c|c|c|c|}
\hline $\begin{array}{l}\text { Spot } \\
\text { no. }\end{array}$ & Protein name & $\begin{array}{l}\text { Protein } \\
\text { function }\end{array}$ & $\begin{array}{l}\text { Accession } \\
\text { no. } \neq\end{array}$ & $\begin{array}{l}\text { Sequence } \\
\text { cov. }(\%)^{\S}\end{array}$ & $\begin{array}{l}\text { Theoretical } \\
\text { Mw (Da)/ } \\
\text { pl }\end{array}$ & $\begin{array}{l}\text { Expression } \\
\text { of protein }\end{array}$ \\
\hline 1 & $\begin{array}{l}\text { RER1 retention in } \\
\text { endoplasmic } \\
\text { reticulum }\end{array}$ & $\begin{array}{l}\text { Secretory } \\
\text { pathway }\end{array}$ & EAW56112.1 & 41 & $21353 / 8.96$ & + \\
\hline 2 & Carboxypeptidase & $\begin{array}{l}\text { Growth } \\
\text { factor } \\
\text { promotion, } \\
\text { Wound } \\
\text { healing }\end{array}$ & AAH63430.1 & 16 & $82269 / 6.20$ & + \\
\hline 3 & $\begin{array}{l}\text { Triosephosphate } \\
\text { isomerase }\end{array}$ & $\begin{array}{l}\text { Glycolysis, } \\
\text { Energy } \\
\text { production }\end{array}$ & $\begin{array}{l}\text { NP } \\
001152759.1\end{array}$ & 74 & $31057 / 5.65$ & + \\
\hline 4 & $\begin{array}{l}\text { Cytochrome b-cl } \\
\text { complex }\end{array}$ & $\begin{array}{l}\text { Inhibition of } \\
\text { apoptosis }\end{array}$ & NP 003357.2 & 39 & $48584 / 8.74$ & - \\
\hline
\end{tabular}

${ }^{\dagger}$ Spot number on the 2-DE gel ${ }^{\ddagger}$ Swiss-Prot accession numbers. SSequence coverage.

\subsection{Treatment with hEGF MSC-CM reduced collagenase activity in human keratinocyte $\mathrm{HaCaT}$ cells}

We performed zymography to examine the collagenase activity in concentrated medium from HaCaT cells cultured with $8 \%$ CM from MSCs, Vector MSCs, and hEGF MSCs. The unstained areas (white bands) in the gels represent collagenase activity. The results revealed that the collagenase activity was $100 \%$, $87 \%$, and $66 \%$ in MSC, Vector MSC, and hEGF MSC-CM-treated cells, respectively (Fig. 6A). To confirm the results of the zymography assay, we performed western blot analysis and qPCR. MMP-1 protein level was found to be decreased in hEGF MSC-CM-treated HaCaT cells (Fig. 6B). The results also showed that MMP-1 mRNA expression levels were 100\%, 95\%, and 31\% in MSC, Vector MSC, and hEGF MSC-CMtreated cells, respectively (Fig. 6C). Taken together, hEGF MSC-CM-treated HaCaT cells showed reduced MMP-1 expression.

\subsection{Effect of hEGF MSC-CM treatment on MAPK protein levels}

We performed western blot analysis to determine the level of MAPK proteins that are involved in MMP-1 expression. The levels of pErk, pJNK, and p-p38 were decreased compared to those of their unphosphorylated forms (Erk, JNK, and p-38) (Fig. 7). In addition, pAkt (associated with cell proliferation) 
level was increased in hEGF MSC-CM-treated HaCaT cells. Furthermore, the levels of other transcription factors ( $p C R E B, N F K B$, and p-c-Fos) were decreased in hEGF MSC-CM-treated HaCaT cells. Taken together, these results indicate that the levels of the MAPK pathway members were decreased following treatment with hEGF MSC-CM.

\section{Discussion}

EGF plays an important role in regulating skin cell homeostasis and proliferation of keratinocyte. It is also a potential regulator of inflammatory and proliferative responses [16]. Receptor tyrosine-protein kinase erbB-4 (ERBB4), a member of the EGF receptor family, is phosphorylated in HaCaT cells following EGF stimulation. ERBB4-knockout mice lack EGF-stimulated signaling, resulting in reduced cell proliferation and significantly reduced epidermal thickness [17]. Collagen is a constituent of the ECM and is located in fibrous tissues such as the skin, ligament, tendon, cornea, blood vessels, bone, and cartilage. Recent studies have shown that collagen promotes cell proliferation, differentiation, expression, and formation of tissues and organs [18].

Many studies have shown that MSCs promote cell proliferation, adhesion, wound healing, and reduce inflammation $[19,20]$. Human umbilical MSCs promote human retinal progenitor cell adherence and differentiation toward retinal neurons [21]. Therefore, we investigated whether hEGF MSCs affect human keratinocyte HaCaT cell proliferation via collagen. In the present study, we first confirmed that hEGF MSCs promote keratinocyte proliferation and migration unlike MSCs. The results also revealed that cell viability rates were increased following treatment with $8 \% \mathrm{CM}$ from hEGF MSCs (Fig. 3). Moreover, we examined the migration of keratinocytes treated with hEGF MSC-CM using the wound-healing assay. The results showed that wound-healing rates also increased (Fig. 4). These results suggest that hEGF MSCs promote cell proliferation and migration in keratinocytes. In general, when cells migrate to the wound, they reconstitute the actin cytoskeleton and secrete various proteases such as MMP-2 and MMP-9 to remodel the ECM [22]. Upregulation of MMP-1 degrades collagen, which is associated with skin conditions and adversely affects skin cell proliferation. Therefore, we examined the changes in the expression of MMP-1 (collagenase), an ECM protease, in hEGF MSC-CM-treated keratinocytes.

Inhibition of collagenase activity is crucial for preventing skin aging [23]. Furthermore, vitamin $\mathrm{C}$ has been reported to have an anti-aging effect on the skin through the inhibition of MMP-1, a well-known collagenase [24]. These studies suggest that inhibition of collagenase may be a key factor in preventing skin aging. MMP-1 breaks down type-I collagen by cleaving peptide bonds between Gly-lle or Gly-Lys of triple helical collagen monomers [25]. To investigate the major factors that affect collagen, including MMP-1, we conducted zymography, western blotting, and qPCR assays. The results showed that the level of collagenase activity and expression level of MMP-1 mRNA and protein were decreased in hEGF MSCCM-treated keratinocytes (Fig. 6). These results suggest that EGF represents a potentially effective factor in preventing skin aging. 
Previous studies have shown that the MAPK pathway regulates MMP-1 expression. For example, cigarette smoke induces the upregulation of MMP-1 expression via the MAPK pathway [14]. Upregulation of MMP-1 is also regulated by the ERK pathway in melanoma cells [26]. Additionally, EGF mediates the expression of MMP-1. Suppression of the EGF ligand regulated the expression of MMP-1 in breast cancer cells [27]. Many studies have shown the involvement of the Akt pathway in cell proliferation and development [28]. Therefore, we performed western blotting to determine the protein expression levels of MAPK (Erk, JNK, and c-Fos) and Akt. The results revealed that MAPK expression levels (phosphorylated forms) were decreased and pAkt was increased (Fig. 7A). Moreover, the expression levels of the other transcription factors were also decreased (Fig. 7B).

2-DE is effective in separating proteins and protein subunits using isoelectric focusing in one dimension and molecular weight in the second dimension [29]. Therefore, we conducted 2-DE proteomic analysis and MALDI-TOF to identify the differentially expressed proteins following treatment of keratinocytes with Vector MSC-CM and hEGF MSC-CM. Approximately 60 protein spots were detected (Fig. 5). Among the differentially expressed proteins spots, carboxypeptidase, which was upregulated, is well-known to promote collagen synthesis [30], fibroblast proliferation [31], and differentiation into myofibroblast [32]. For example, the aortic carboxypeptidase-like protein, which is an ECM protein, is expressed in collagenrich tissues and promotes embryonic development and dermal wound healing during mouse embryogenesis [33]. Therefore, we hypothesize that upregulation of carboxypeptidase affects HaCaT cell proliferation induced by hEGF MSCs.

\section{Conclusion}

In summary, we studied the effect of hEGF MSCs on keratinocytes and report the following observations. First, hEGF MSCs enhanced cell proliferation and migration of HaCaT cells. Second, hEGF MSCs induced carboxypeptidase, which promotes cell proliferation. Finally, hEGF MSCs reduced MMP-1 expression via the MAPK pathway and induced Akt. Taken together, the results of the present study demonstrate that hEGF MSCs promote cell proliferation and reduce collagenase activity in human keratinocyte HaCaT cells via the MAPK pathway.

\section{Abbreviations}

human epidermal growth factor (hEGF), matrix metalloproteinase (MMP), mitogen-activated protein kinase (MAPK), mesenchymal stem cells (MSCs), conditioned medium (CM), two-dimensional electrophoresis (2-DE), epidermal growth factor receptor (EGFR), quantitative polymerase chain reaction (qPCR), matrix-assisted laser desorption/ionization time-of-flight (MALDI-TOF)

\section{Declarations}

\section{Funding}


This work was supported by a grant from the Business for Cooperative R\&D between Industry, Academy, and Research Institutes (Grant no. C0443066) funded by the Korean Small and Medium Business Administration in 2016, and the Basic Science Research Program through the gs2:National Research Foundation of Korea funded by the Ministry of Education, Science and Technology (NRF2014R1A6A3A04054307).

\section{Ethical statement}

\section{Conflicts of Interest}

All authors declared that there are no conflicts of interest.

\section{Ethical approval}

All authors clearly declared that this study didn't contain experiments using animal or human.

\section{Author contributions}

Jeong Hyun Lee: Designed and performed experiments, wrote manuscript.

Chang Min Lee: Designed and performed experiments, wrote manuscript.

Yong Jun Choi: performed experiments.

See-Hyoung Park: Designed and performed experiments, wrote manuscript, analyzed the data. Myeong Jin Nam: Getting funds, supervised this study.

\section{Data availability statement}

All data generated or analyzed during this study are included in this published article

\section{References}

1. Hua J, Yu H, Dong W, Yang C, Gao Z, Lei A, Sun Y, Pan S, Wu Y, Dou Z (2009) Characterization of mesenchymal stem cells (MSCs) from human fetal lung: potential differentiation of germ cells. Tissue Cell 41:448-455. doi:10.1016/j.tice.2009.05.004

2. Chen Y, Shao JZ, Xiang LX, Dong XJ, Zhang GR (2008) Mesenchymal stem cells: a promising candidate in regenerative medicine. Int $\mathrm{J}$ Biochem Cell Biol 40:815-820. doi:10.1016/j.biocel.2008.01.007

3. Ding DC, Chang YH, Shyu WC, Lin SZ (2015) Human umbilical cord mesenchymal stem cells: a new era for stem cell therapy. Cell Transplant 24:339-347. doi:10.3727/096368915X686841

4. Qi K, Li N, Zhang ZY, Melino G (2018) Tissue regeneration: The crosstalk between mesenchymal stem cells and immune response. Cell Immunol 326:86-93. doi:10.1016/j.cellimm.2017.11.010 
5. Wang Z, Wang Y, Wang Z, Gutkind JS, Wang Z, Wang F, Lu J, Niu G, Teng G, Chen X (2015) Engineered mesenchymal stem cells with enhanced tropism and paracrine secretion of cytokines and growth factors to treat traumatic brain injury. Stem Cells 33:456-467. doi:10.1002/stem.1878

6. Shree N, Venkategowda S, Venkatranganna MV, Bhonde RR (2017) Treatment with adipose derived mesenchymal stem cells and their conditioned media reverse carrageenan induced paw oedema in db/db mice. Biomed Pharmacother 90:350-353. doi:https://doi.org/10.1016/j.biopha.2017.03.090

7. Carpenter G, Cohen S (1990) EPIDERMAL GROWTH-FACTOR. J Biol Chem 265:7709-7712

8. Han L, Ma Q, Li J, Liu H, Li W, Ma G, Xu Q, Zhou S, Wu E (2011) High glucose promotes pancreatic cancer cell proliferation via the induction of EGF expression and transactivation of EGFR. PLoS One 6:e27074. doi:10.1371/journal.pone.0027074

9. Al Moustafa AE, Achkhar A, Yasmeen A (2012) EGF-receptor signaling and epithelial-mesenchymal transition in human carcinomas. Front Biosci (Schol Ed) 4:671-684

10. Zhou JJ, Liu HS, Zhou S, He P, Liu X (2016) Adaptor protein APPL1 interacts with EGFR to orchestrate EGF-stimulated signaling. Science Bulletin 61:1504-1512. doi:10.1007/s11434-016-1157-0

11. Hamaoka Y, Negishi M, Katoh $\mathrm{H}$ (2016) EphA2 is a key effector of the MEK/ERK/RSK pathway regulating glioblastoma cell proliferation. Cell Signal 28:937-945. doi:https://doi.org/10.1016/j.cellsig.2016.04.009

12. Liu Y, Zhang H, Yan L, Du W, Zhang M, Chen H, Zhang L, Li G, Li J, Dong Y, Zhu D (2018) MMP-2 and MMP-9 contribute to the angiogenic effect produced by hypoxia/15-HETE in pulmonary endothelial cells. J Mol Cell Cardiol 121:36-50. doi:https://doi.org/10.1016/j.yjmcc.2018.06.006

13. Pittayapruek P, Meephansan J, Prapapan O, Komine M, Ohtsuki M (2016) Role of Matrix Metalloproteinases in Photoaging and Photocarcinogenesis. Int J Mol Sci 17. doi:10.3390/ijms17060868

14. Carver PI, Anguiano V, D’Armiento JM, Shiomi T (2015) Mmp1a and Mmp1b are not functional orthologs to human MMP1 in cigarette smoke induced lung disease. Exp Toxicol Pathol 67:153-159. doi:https://doi.org/10.1016/j.etp.2014.11.004

15. Morris JL, Cross SJ, Lu Y, Kadler KE, Lu Y, Dallas SL, Martin P (2018) Live imaging of collagen deposition during skin development and repair in a collagen I - GFP fusion transgenic zebrafish line. Developmental Biology doi. https://doi.org/10.1016/j.ydbio.2018.06.001

16. Schneider MR, Werner S, Paus R, Wolf E (2008) Beyond wavy hairs: the epidermal growth factor receptor and its ligands in skin biology and pathology. Am J Pathol 173:14-24. doi:10.2353/ajpath.2008.070942

17. Hoesl C, Röhrl JM, Schneider MR, Dahlhoff M (2018) The receptor tyrosine kinase ERBB4 is expressed in skin keratinocytes and influences epidermal proliferation. Biochimica et Biophysica Acta (BBA) -. General Subjects 1862:958-966. doi:https://doi.org/10.1016/j.bbagen.2018.01.017

18. Bhagwat PK, Dandge PB (2018) Collagen and collagenolytic proteases: A review. Biocatal Agric Biotechnol 15:43-55. doi:https://doi.org/10.1016/j.bcab.2018.05.005 
19. Amini A, Pouriran R, Abdollahifar M-A, Abbaszadeh HA, Ghoreishi SK, Chien S, Bayat M (2018) Stereological and molecular studies on the combined effects of photobiomodulation and human bone marrow mesenchymal stem cell conditioned medium on wound healing in diabetic rats. $J$ Photochem Photobiol B 182:42-51. doi:https://doi.org/10.1016/j.jphotobiol.2018.03.010

20. Pouya S, Heidari M, Baghaei K, Asadzadeh Aghdaei H, Moradi A, Namaki S, Zali MR, Hashemi SM (2018) Study the effects of mesenchymal stem cell conditioned medium injection in mouse model of acute colitis. Int Immunopharmacol 54:86-94. doi:https://doi.org/10.1016/j.intimp.2017.11.001

21. Zhang M, Zhang F, Sun J, Sun Y, Xu L, Zhang D, Wang Z, He W (2017) The condition medium of mesenchymal stem cells promotes proliferation, adhesion and neuronal differentiation of retinal progenitor cells. Neurosci Lett 657:62-68. doi:https://doi.org/10.1016/j.neulet.2017.07.053

22. Kheng LH, Rahim AB, Leo VI, Shatarupa D, Lim TC, Uemura T, Igarashi K, Common J, Vardy LA (2018) Polyamine regulator AMD1 promotes cell migration in epidermal wound healing. Journal of Investigative Dermatology. doi:https://doi.org/10.1016/j.jid.2018.05.029

23. Geeta G, Widodo WS, Widowati W, Ginting CN, Lister INE, Armansyah A, Girsang E (2019) Comparison of Antioxidant and Anti. -collagenase Activity of Genistein and Epicatechin

24. Ganceviciene R, Liakou Al, Theodoridis A, Makrantonaki E, Zouboulis CC (2012) Skin anti-aging strategies. Dermato-endocrinology 4:308-319. doi:10.4161/derm.22804

25. Fields GB (2013) Interstitial collagen catabolism. J Biol Chem 288:8785-8793. doi:10.1074/jbc.R113.451211

26. Huntington JT, Shields JM, Der CJ, Wyatt CA, Benbow U, Slingluff CL Jr, Brinckerhoff CE (2004) Overexpression of collagenase 1 (MMP-1) is mediated by the ERK pathway in invasive melanoma cells: role of BRAF mutation and fibroblast growth factor signaling. J Biol Chem 279:33168-33176. doi:10.1074/jbc.M405102200

27. Park S, Jung HH, Park YH, Ahn JS, Im Y-H (2011) ERK/MAPK pathways play critical roles in EGFR ligands-induced MMP1 expression. Biochem Biophys Res Commun 407:680-686. doi:https://doi.org/10.1016/j.bbrc.2011.03.075

28. Shi G, Tang N, Qiu J, Zhang D, Huang F, Cheng Y, Ding K, Li W, Zhang P, Tan X (2017) Irisin stimulates cell proliferation and invasion by targeting the PI3K/AKT pathway in human hepatocellular carcinoma. Biochem Biophys Res Commun 493:585-591.

doi:https://doi.org/10.1016/j.bbrc.2017.08.148

29. Anderson NG, Anderson NL (1978) Analytical techniques for cell fractions: XXI. Two-demensional analysis of serum and tissue proteins: Multiple isoelectric focusing. Anal Biochem 85:331-340. doi:https://doi.org/10.1016/0003-2697(78)90229-4

30. Abe M, Kurosawa M, Ishikawa O, Miyachi Y (2000) Effect of mast cell-derived mediators and mast cell-related neutral proteases on human dermal fibroblast proliferation and type I collagen production. J Allergy Clin Immunol 106:S78-S84

31. Gruber BL, Kew RR, Jelaska A, Marchese MJ, Garlick J, Ren S, Schwartz LB, Korn JH (1997) Human mast cells activate fibroblasts: tryptase is a fibrogenic factor stimulating collagen messenger 
ribonucleic acid synthesis and fibroblast chemotaxis. J Immunol 158:2310-2317

32. Gailit J, Marchese MJ, Kew RR, Gruber BL (2001) The differentiation and function of myofibroblasts is regulated by mast cell mediators. Journal of Investigative Dermatology 117:1113-1119. DOI 10.1046/j.1523-1747.2001.15211.x doi

33. Layne MD, Yet SF, Maemura K, Hsieh CM, Bernfield M, Perrella MA, Lee ME (2001) Impaired abdominal wall development and deficient wound healing in mice lacking aortic carboxypeptidaselike protein. Mol Cell Biol 21:5256-5261. doi:10.1128/MCB.21.15.5256-5261.2001

\section{Figures}

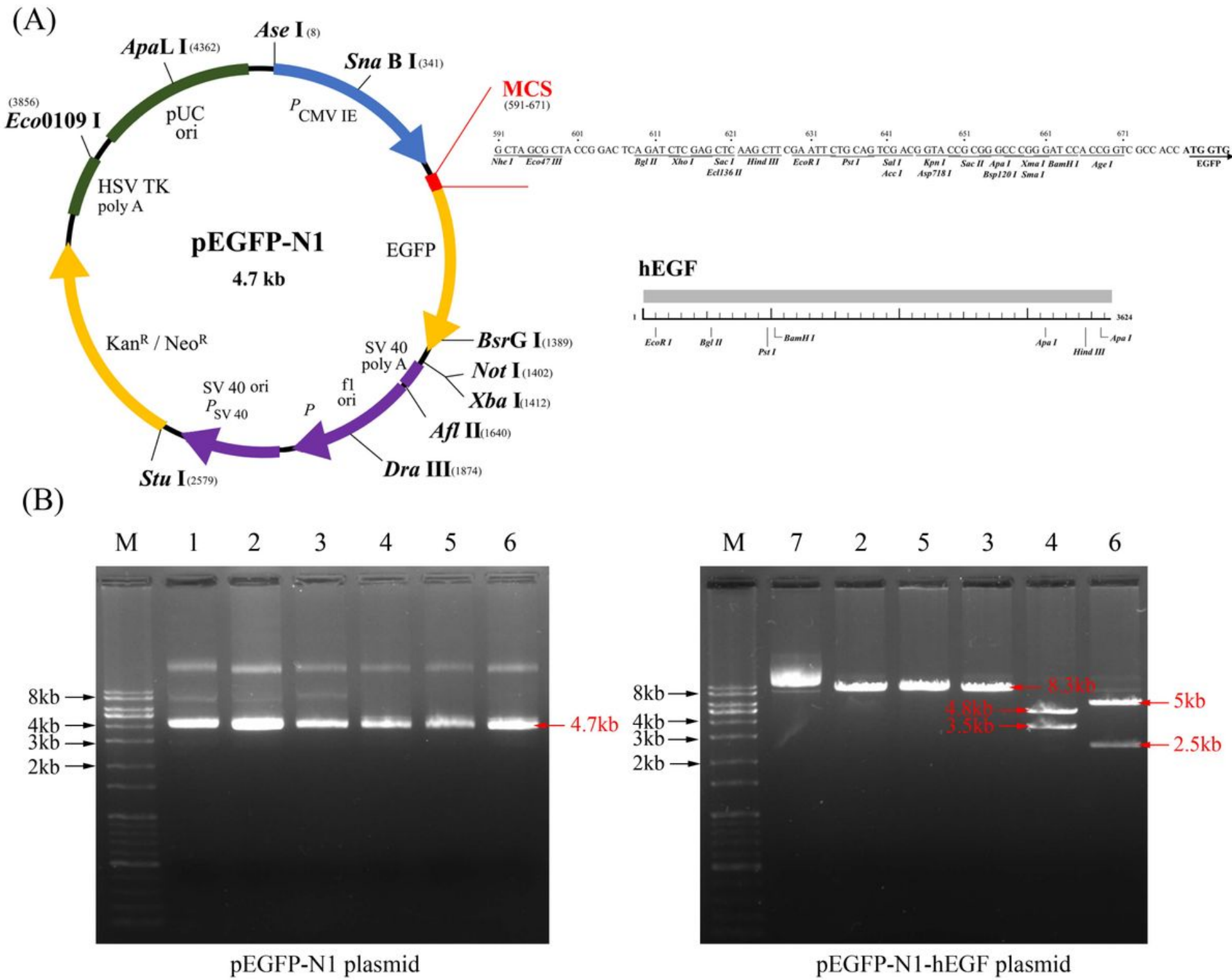

\section{Figure 1}

(A) pEGFP-N1 plasmid map and hEGF gene information. (B) pEGFP-N1 and pEGFP-N1-hEGF plasmids were digested with restriction enzymes. The pEGFP-N1 plasmid (4.7 kb) was digested into a single 
fragment by Nhe1, Xho1, EcoR1, Kpn1, and BamH1. pEGFP-N1-hEGF plasmid (8.3 kb) was digested into a single segment by Nhe1, Kpn1, and Xho1. In addition, it was cut by EcoR1 to $4.3 \mathrm{~kb}$ and $3.5 \mathrm{~kb}$ fragments, and by BamH1 into $5 \mathrm{~kb}$ and $2.5 \mathrm{~kb}$ fragments. (M: marker, 1: pEGFP-N1-Control plasmid, 2: Nhe1, 3 : Xho1, 4: EcoR1, 5: Kpn1, 6: BamH1, 7: pEGFP-N1-hEGF plasmid)

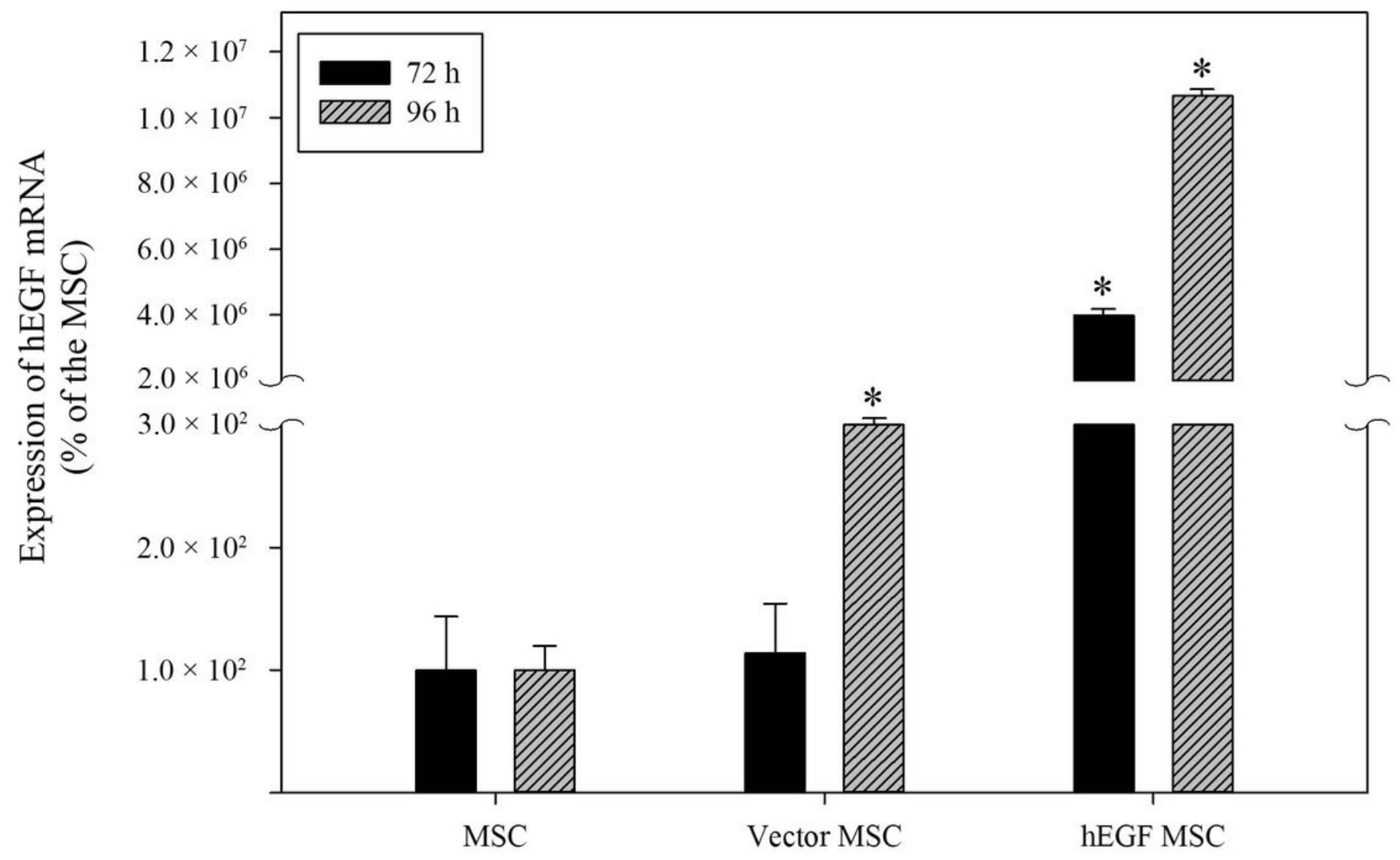

Figure 2

qPCR assay was used to determine mRNA expression of hEGF in hEGF plasmid-transfected MSCs. Expression of hEGF mRNA was increased in MSCs transfected with hEGF plasmid at both 72 and $96 \mathrm{~h}$. Data represent the mean \pm standard deviation (SD) of three independent experiments. All data are significantly different from that of the control MSCs $\left({ }^{\star} p<0.05\right)$. 
(A)

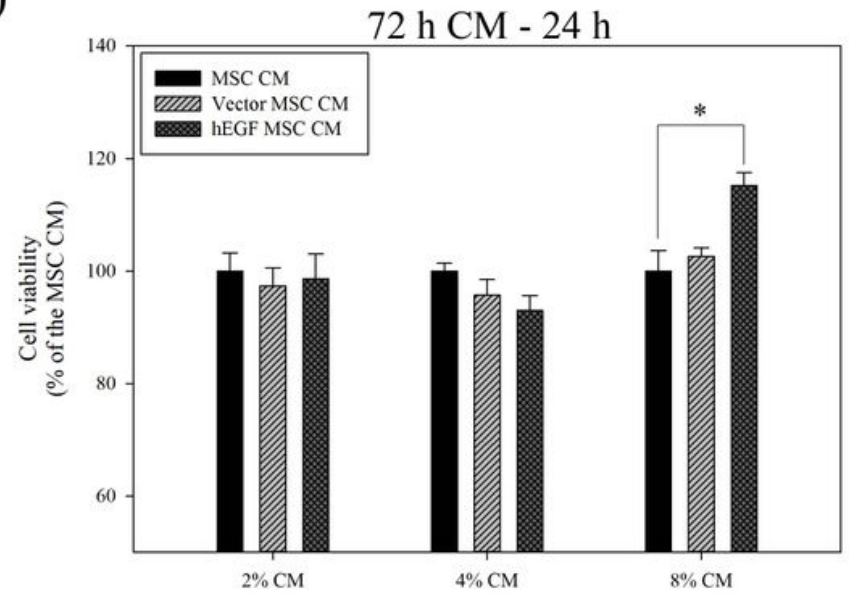

(B)

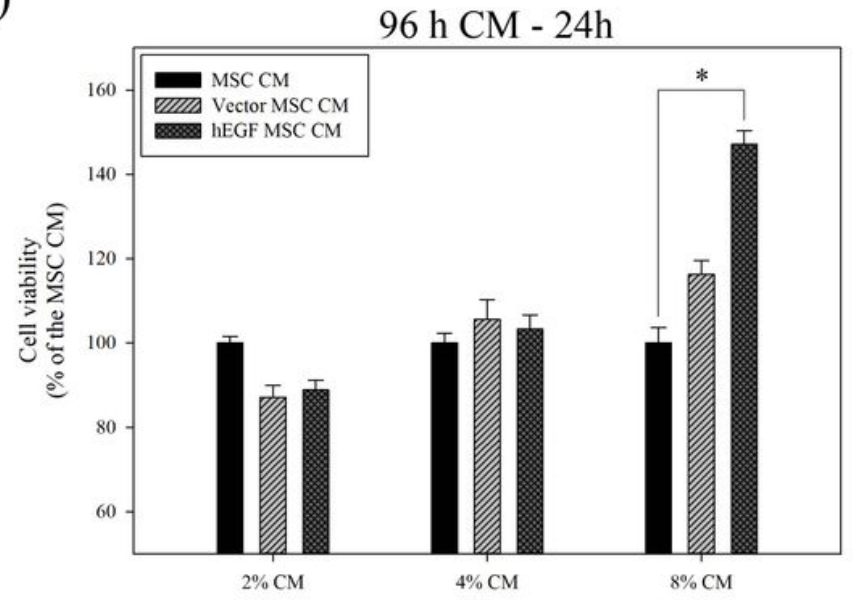

$72 \mathrm{~h} \mathrm{CM}-48 \mathrm{~h}$

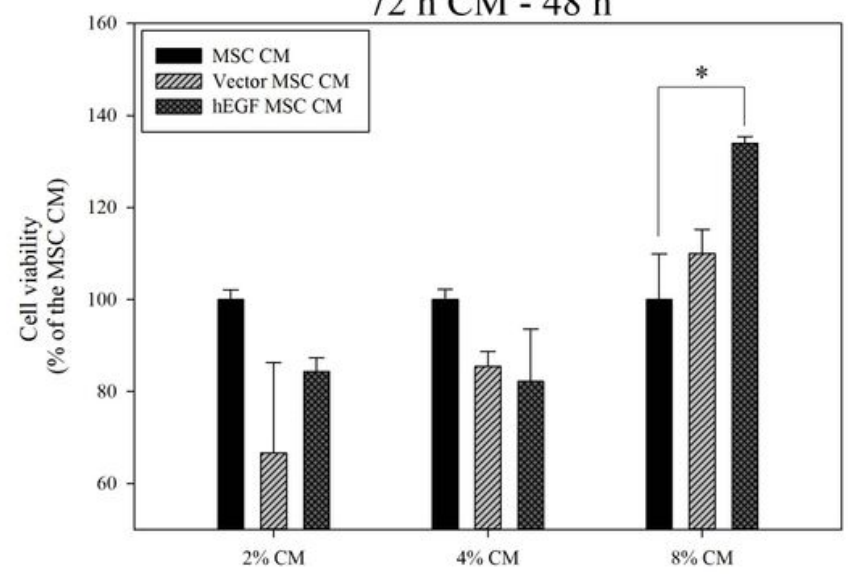

$96 \mathrm{~h} \mathrm{CM}-48 \mathrm{~h}$

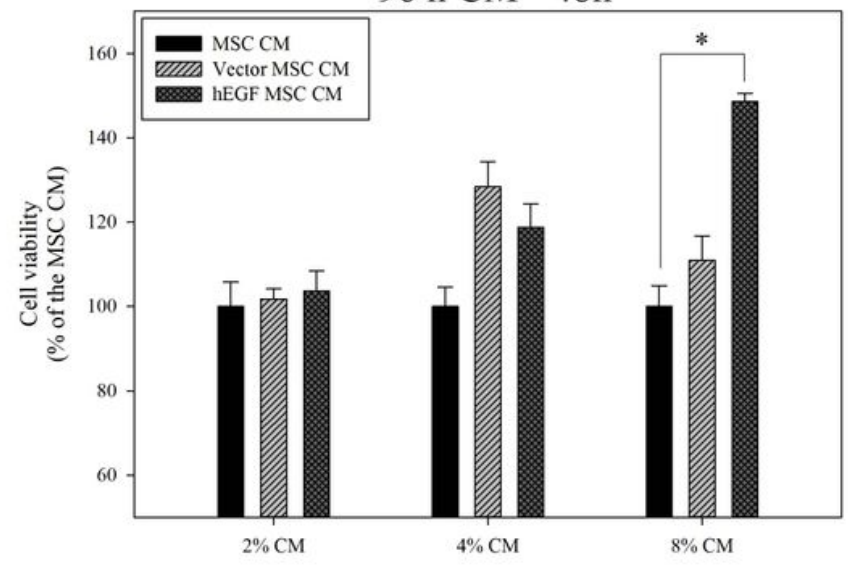

Figure 3

(A) Cell viability of HaCaT cells was measured using a WST-1 assay. HaCaT cells were treated with CM from cells cultured for $72 \mathrm{~h}$. There was no marked change with $2 \%$ and $4 \% \mathrm{CM}$, whereas the cell viability in $8 \%$ hEGF MSC-CM-treated HaCaT cells was increased compared to that in the MSC-CM-treated group. (B) $\mathrm{HaCaT}$ cells were treated with $\mathrm{CM}$ from cells cultured for $96 \mathrm{~h}$. The results showed that cell viability was markedly increased in $8 \%$ hEGF MSC-CM-treated HaCaT cells. All data represent the mean \pm SD of three independent experiments. All data are significantly different from that of the MSC-CM-treated group $\left({ }^{*} \mathrm{p}<0.05\right)$. 
(A)

$72 \mathrm{~h} \mathrm{CM}$

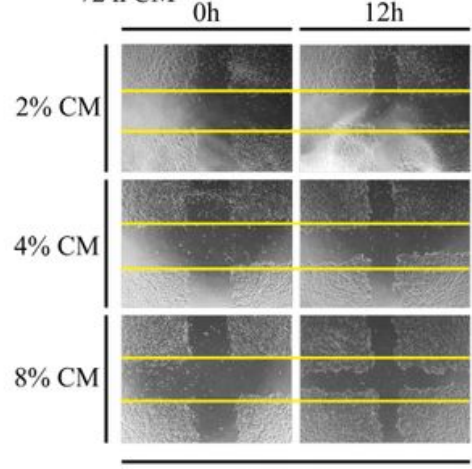

MSC CM

(B)

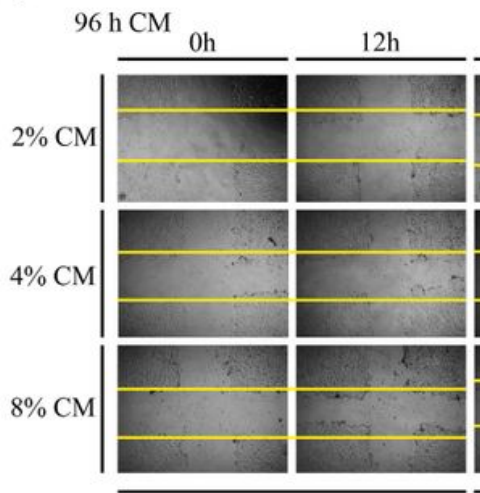

MSC CM oh

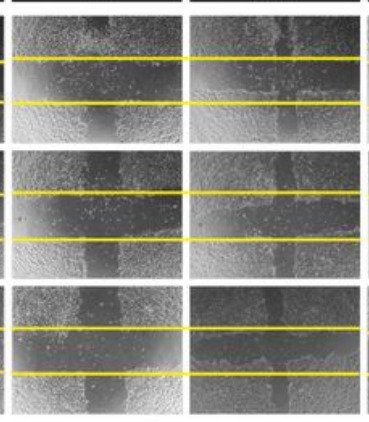

Vector MSC CM

oh

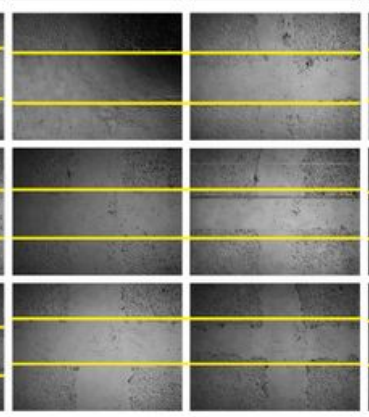

Vector MSC CM oh

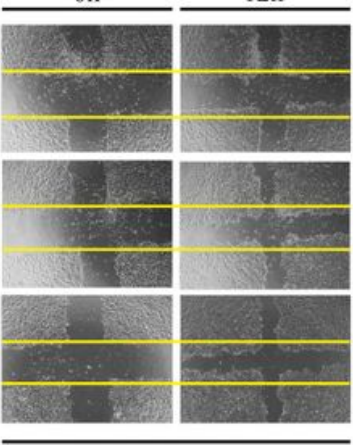

hEGF MSC CM

oh

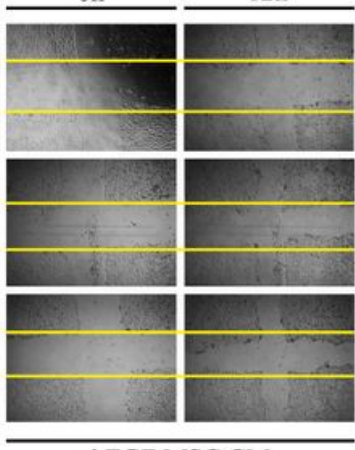

hEGF MSC CM
(C)

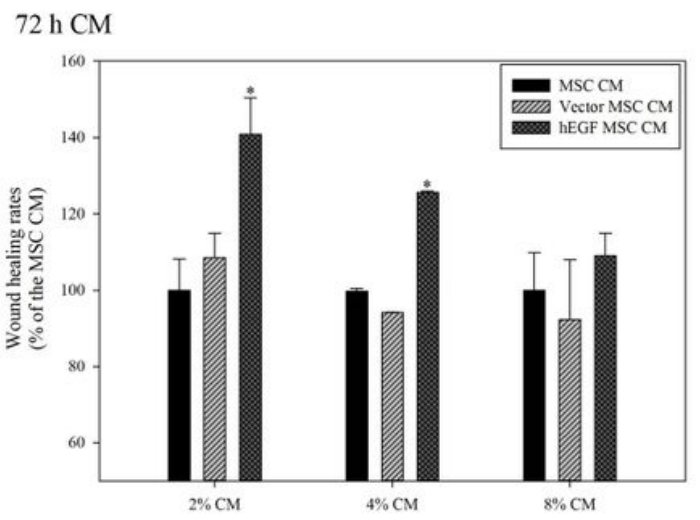

(D)

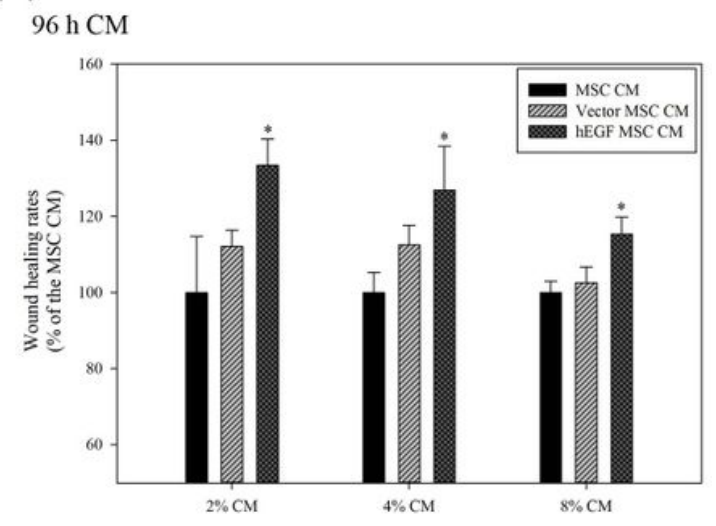

Figure 4

Wound-healing assay was performed using HaCaT cells treated with MSC-CM, Vector MSC-CM, and hEGF MSC-CM for $12 \mathrm{~h}$. Each medium was mixed in serum-free medium and incubated for $72 \mathrm{~h}(\mathrm{~A})$, and $96 \mathrm{~h}$ (B). The results showed increased HaCaT cell migration following hEGF MSC-CM treatment compared to MSC-CM treatment. The bar graph shows the wound-healing rates, which represents the area covered by the cell after $12 \mathrm{~h}$. Wound healing was increased in the hEGF MSC-CM-treated HaCaT cells compared to that in the MSC-CM-treated HaCaT cells (C, and D). Experiment were independently performed at least three times. ${ }^{*} \mathrm{p}<0.05$ versus the MSC-CM-treated group. 


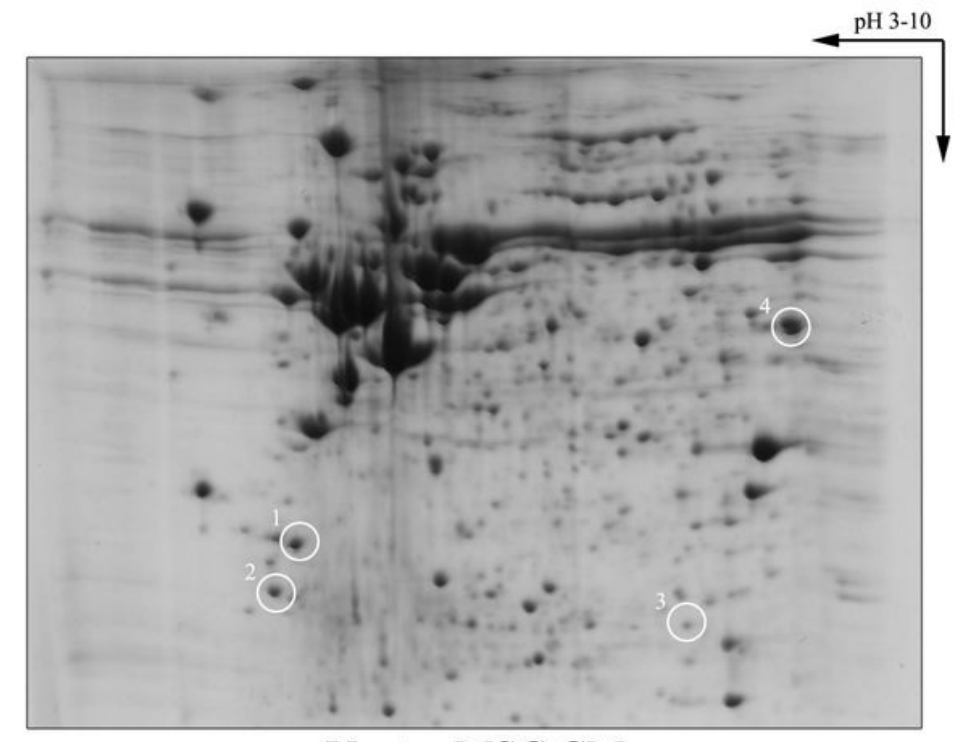

Vector MSC CM

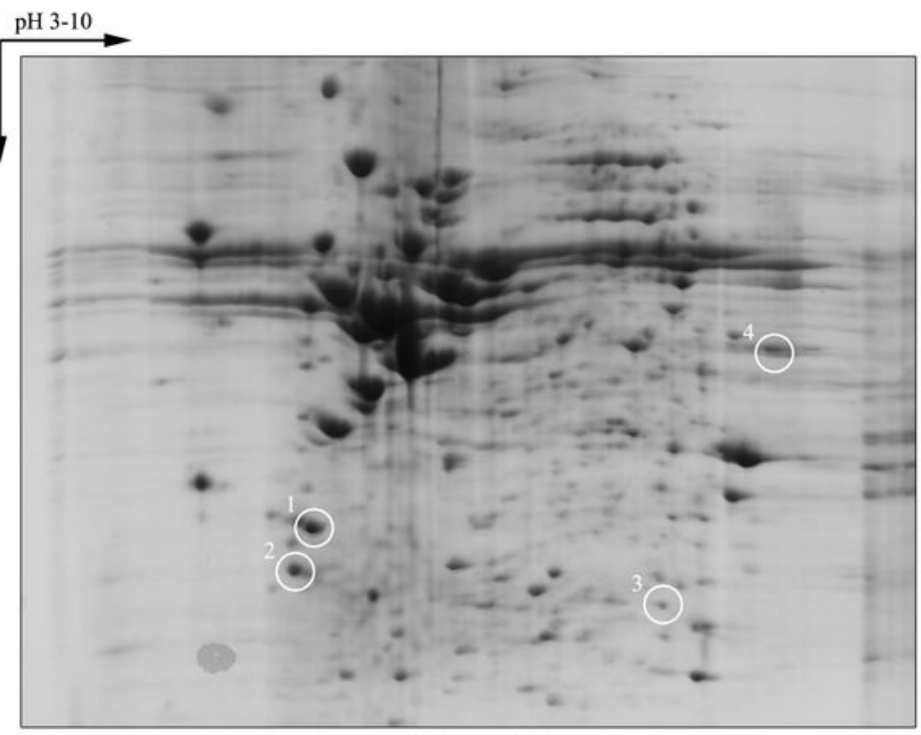

hEGF MSC CM

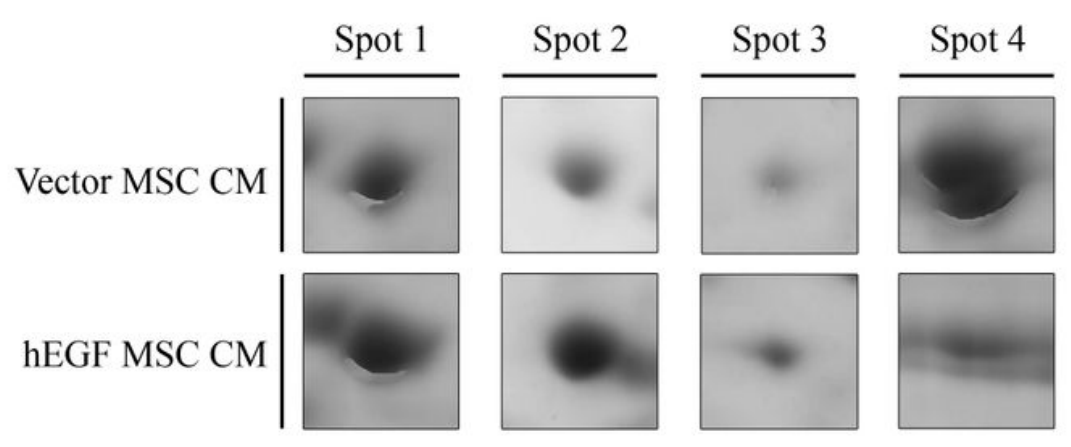

\section{Figure 5}

2-DE proteomic analysis was used to identify the differentially expressed proteins between the Vector MSC-CM- and hEGF MSC-CM-treated HaCaT cells. Differential proteins are indicated with an arrow sign. Selected proteins were identified via MALDO-TOF analysis (Table 1). The results show three protein spots (RER1 retention in endoplasmic reticulum, carboxypeptidase, and triosephosphate isomerase) that were upregulated and one protein spot (Cytochrome b-cl complex) that was downregulated. 
(A)
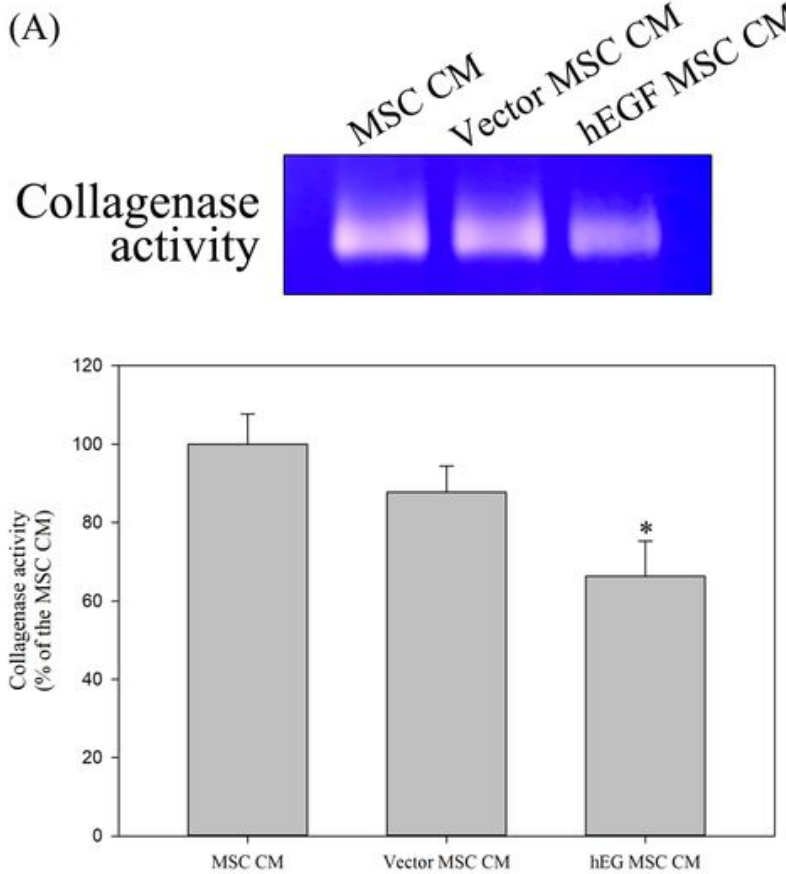

(B)

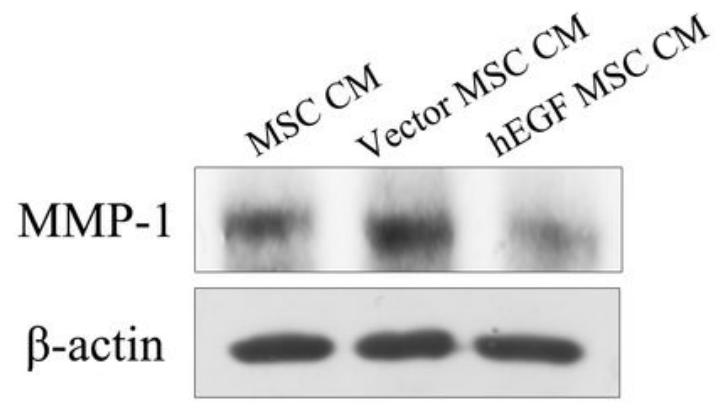

(C)

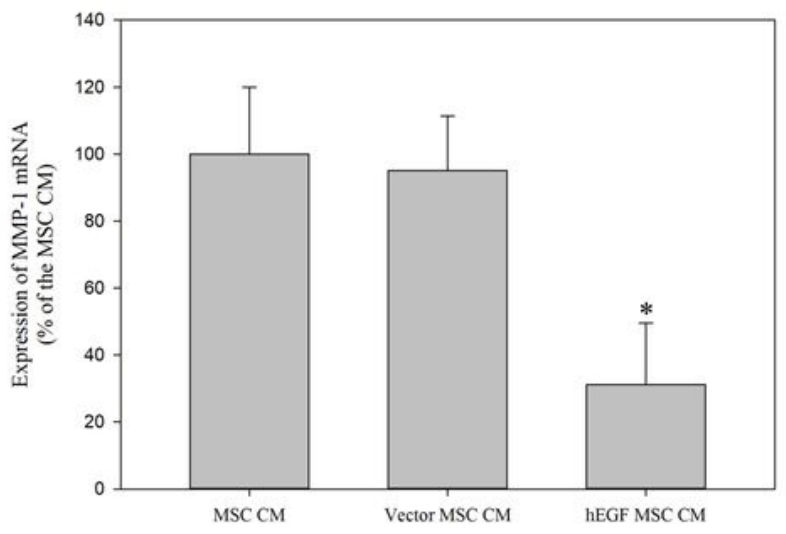

Figure 6

(A) Collagenase activity (MMP-1 activity) was measured by zymography assay. The results revealed that collagenase activity was decreased in $8 \%$ hEGF MSC-CM-treated HaCaT cells. Experiments were independently performed at least three times. ${ }^{\star} \mathrm{p}<0.05$ versus the MSC-CM-treated group. (B) MMP-1 protein level was determined by western blotting. The expression of MMP-1 was decreased following hEGF MSC-CM treatment. (C) Expression of MMP-1 mRNA was measured by qPCR. The bar graph 
showing that the expression of MMP-1 mRNA was decreased in 8\% hEGF MSC-CM-treated HaCaT cells. Experiments were independently performed at least three times. ${ }^{*} p<0.05$ versus the MSC-CM-treated group.

(A)
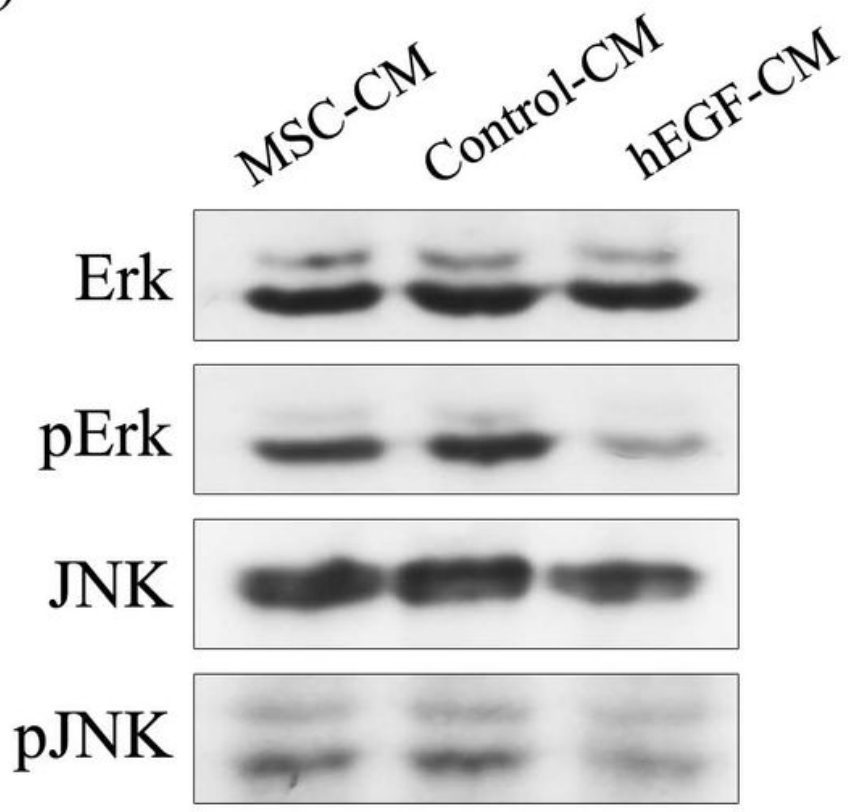

p38

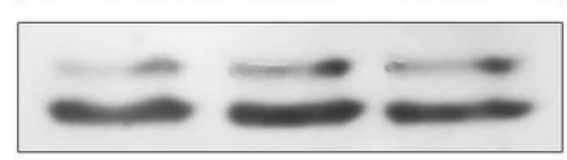

p-p38

Akt
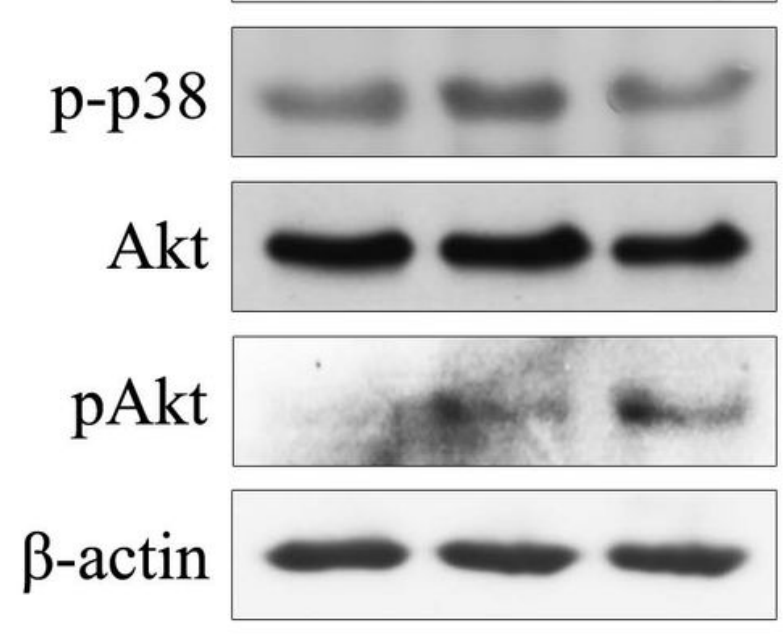

(B)

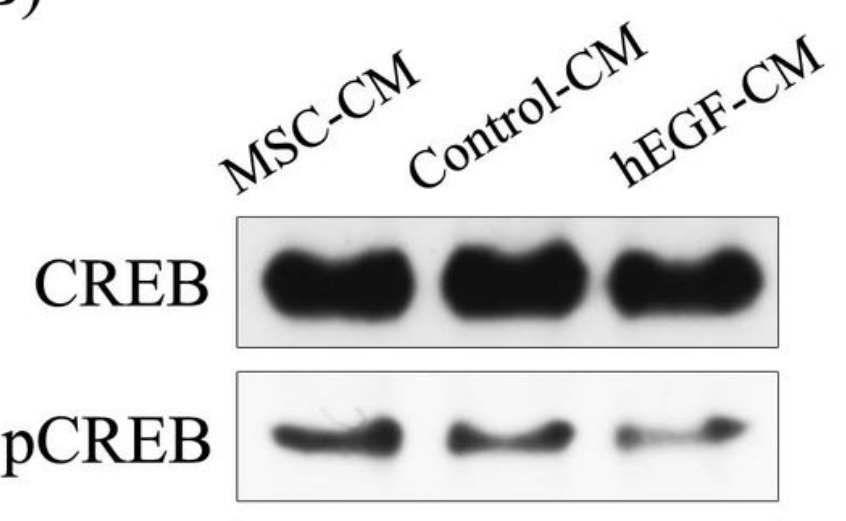

NFkB(p65)

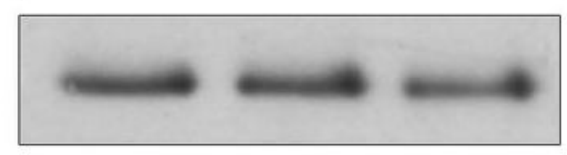

p-c-Fos

$\beta$-actin
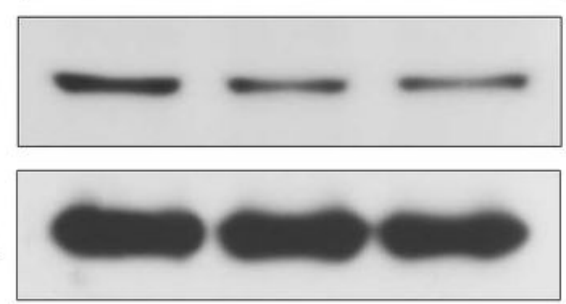

\section{Figure 7}

(A) MAPK protein levels were determined by western blotting. The levels of MAPK pathway proteins ( $p$ Erk, pJNK, and p-p38) were decreased, whereas pAkt expression level was increased. (B) HaCaT cells were treated various $\mathrm{CMs}$ (as described in the Fig. $7 \mathrm{~A}$ ) for 24 . The protein levels of various transcription factors (pCREB, NFkB, and p-c-Fos) were found to be decreased. 